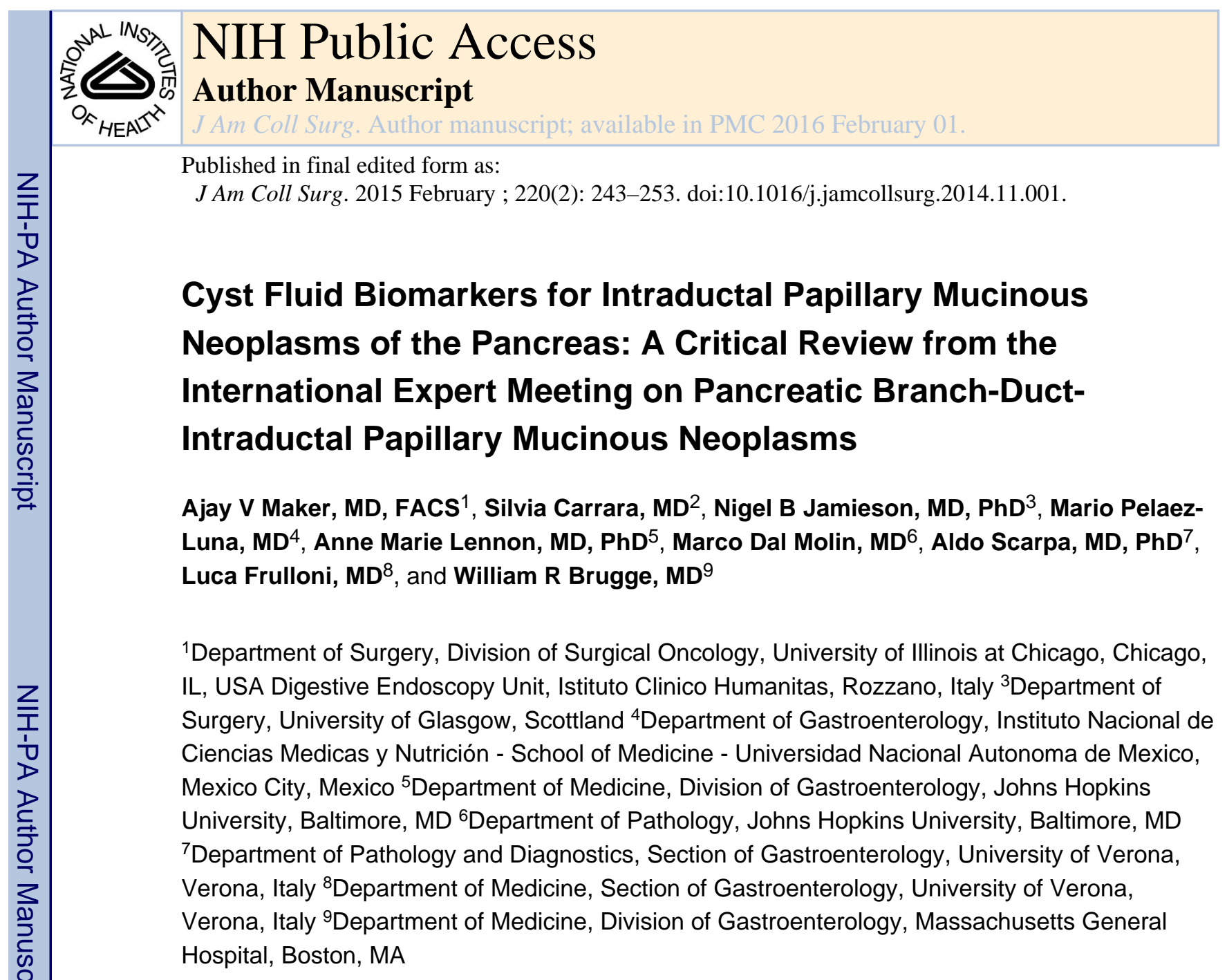

\title{
Introduction
}

The recognition of pancreatic cysts and intraductal papillary mucinous neoplasms of the pancreas (IPMN) has increased largely secondary to greater utilization of high-quality crosssectional abdominal imaging. ${ }^{1,2}$ Although the general characteristics of IPMNs, radiographic diagnosis, cyst fluid composition, and their delineation from other pancreatic tumors have been well established, several issues regarding their growth and progression into malignancy remain poorly described. The degree of neoplastic transformation within IPMN is highly variable, from those with an entirely innocuous cell population typically resembling gastric epithelium and lacking any cytologic atypia, to those that have progressively increasing degrees of cytoarchitectural atypia. Though some patients with highly dysplastic and invasive IPMN may present with clinical symptoms or characteristic

(C) 2014 by the American College of Surgeons. All rights reserved.

Correspondence address: Ajay V. Maker, 835 S. Wolcott Ave. MC 790, Chicago, IL 60612, (t) 773-296-7379, (f) 773-296-7731, amaker@uic.edu.

Publisher's Disclaimer: This is a PDF file of an unedited manuscript that has been accepted for publication. As a service to our customers we are providing this early version of the manuscript. The manuscript will undergo copyediting, typesetting, and review of the resulting proof before it is published in its final citable form. Please note that during the production process errors may be discovered which could affect the content, and all legal disclaimers that apply to the journal pertain.

Disclosure Information: Nothing to disclose. 
radiographic findings, including jaundice, an associated pancreatic mass, or main pancreatic duct dilation; increasingly IPMN are incidentally discovered. Once IPMN are radiographically diagnosed, there is currently no reliable way to determine the level of epithelial dysplasia or to predict the time frame of progression to high-grade dysplasia or cancer. ${ }^{3-6}$ A biologic marker of IPMNs is urgently needed - one that can be easily obtained and tested without significant morbidity for the patient.

An evidence-based expert meeting on pancreatic branch-duct IPMNs (BD-IMPN) was held in Verona, Italy and the authors reviewed the current role of existing technologies and molecular markers for predicting the biological behavior of IPMNs. The status of endoscopic ultrasound (EUS) and EUS-guided fine needle aspiration (FNA) cytology, cyst fluid biochemistry, mucins, cytokines, DNA, and microRNA profiles were critically reviewed by the group in order to identify the most promising clinically relevant biomarkers, and to target analyses for further development.

\section{Endoscopic ultrasound}

Endoscopic ultrasound (EUS) is a highly sensitive imaging modality for the evaluation of pancreatic cystic lesions that was developed as a diagnostic modality, but rapidly gained a role in IPMN for morphologic assessment and for its interventional capabilities, namely aspiration of cyst fluid and fine-needle aspiration (FNA). Diagnosis of IPMN based solely on EUS findings requires attention to cyst size, characteristics of the cyst wall, internal characteristics of the cyst, communication with the MPD, and the existence of any background lesions. Using EUS morphologic parameters, the sensitivity, specificity and accuracy to differentiate between benign and malignant, or potentially malignant, cystic lesions has been reported to be between $56 \%-91 \%, 45 \%-60 \%$ and $51 \%-72 \%$, respectively ${ }^{7,8}$ Although evaluation and the differential diagnosis of cystic lesions based solely on EUS morphology is feasible; inter-observer variability, operator dependency, and moderate diagnostic performance limit its accuracy without the addition of cyst fluid aspiration and FNA cytology, especially for determination of high-risk IPMN without overt malignant features.

\section{Cyst Fluid Cytology Analysis}

Information gained from EUS morphology is enhanced in the context of additional clinical information, cross-sectional imaging, and cyst fluid analysis. EUS-FNA is a safe and accurate technique to obtain cytological or histological samples from pancreatic masses and it can also be used to aspirate fluid from cystic lesions. Diagnostic accuracy has varied considerably among studies and may reflect differences in sampling methods, cytopathologist skill, and success in clinical pathological correlation. ${ }^{7}$ Cyst fluid cytology is an accurate test for the diagnosis of a malignant pancreatic cystic lesion, ${ }^{9}$ however, the sensitivity of cytology is often hampered by the low cellular content of the pancreatic cyst fluid. Additionally, distinguishing lesional cells from gastrointestinal contamination is often difficult, though crucial, to making an accurate interpretation. ${ }^{10,11}$ The positive predictive value of EUS-FNA for invasive malignancy is very high, however, its utility to determine the level of dysplasia in mucinous lesions remains to be improved. ${ }^{5}$ The main issue is that in 
the absence of frank malignancy, determination of high from low or intermediate-grade dysplasia is difficult to determine from FNA cytology.

The neoplastic epithelial cells of serous cystic neoplasms are rarely identified on EUS-FNA specimens ${ }^{12}$ though a recent report has identified vascular endothelial growth factor-A (VEGF-A) and VEGF receptor 2 to be overexpressed only in these cysts. ${ }^{13}$ The cytological features of IPMNs and MCNs are similar to each other, showing mucinous neoplastic epithelial cells. MCNs may have large secretory epithelial cells with evidence of mucin secretion or atypia. ${ }^{14}$ Unfortunately, the cellularity of the cyst fluid is seldom sufficient to distinguish IPMN from MCN. ${ }^{10}$ EUS-FNA of pancreatic cystic lesions has a very low false positive rate, but a high false negative rate in the diagnosis of malignancy, mainly due to sampling error, occurring in up to $30 \%$ of cystic lesions vs. $12 \%$ of solid lesions. ${ }^{15}$ The combination of no high-risk stigmata, no worrisome features, and no high-grade atypia on cytology have comprised an EUS+EUS-FNA "triple test," that may provide a negative predictive value of $99 \%$ for conservative management. ${ }^{16}$ EUS-FNA cytology is a screening tool that contributes to the evaluation of pancreatic cysts and BD-IPMN. When positive for malignancy, it is critically useful, however, when negative, its utility in risk stratification and surgical decision making for IPMN is limited. ${ }^{5}$ In this setting, additional analysis of the cyst fluid for markers of malignancy is far more useful.

\section{Cyst Fluid Tumor Markers}

The fluid contents of cystic lesions of the pancreas are often analyzed for cytology, ${ }^{17}$ however, the low cellular content of cyst fluid has hampered the use of cytologic analysis. A variety of cyst fluid markers have been studied to help differentiate between the major types of cystic neoplasms (table 1). ${ }^{18}$ The presence of extracellular mucin in aspirated cyst fluid is moderately predictive of a mucinous neoplasm. ${ }^{19}$ Furthermore, cyst fluid tumor markers such as carcinoembryonic antigen (CEA), CA 72-4, CA 125, CA 19-9, and CA 15-3 have been tested for their use in the diagnosis of pancreatic cystic neoplasms. ${ }^{20}$ Of these, cyst fluid CEA concentration is reported to be the most accurate marker to differentiate mucinous from non-mucinous pancreatic cystic lesions with an accuracy of $79 \%$ and sensitivity and specificity of $73 \%$ and $84 \%$, respectively. The 2012 international consensus guidelines restated that a cutoff value of $192-200 \mathrm{ng} / \mathrm{mL}$ is approximately $80 \%$ accurate for the diagnosis of a mucinous pancreatic cystic lesion. ${ }^{11}$ It is important to note that though cyst fluid CEA levels help differentiate serous from mucinous cystic lesions, the value will not differentiate between IPMN and MCN, or correlate with the level of dysplasia or malignancy.

\section{Cyst Fluid Amylase}

Theoretically, one may speculate that the cyst fluid amylase concentration might be higher in IPMNs than MCNs, as IPMNs involve the pancreatic duct and MCNs do not. However, cyst fluid amylase concentration has been shown not to distinguish MCNs from IPMNs. ${ }^{9}, 11$

\section{Cyst Fluid Mucin Analysis}

Mucins (MUCs) are heavily glycosylated high-molecular-weight glycoproteins whose polypeptide chains have domains rich in threonine and serine. ${ }^{21-23}$ Pancreatic MUCs play 
an important role in the lubrication, moisturization, and protection of the duct lining. MUCs are also involved in the renewal and differentiation of the epithelium, modulation of cell adhesion, and cell signaling. Alterations in MUC glycosylation have been observed in tumor tissues and it has been hypothesized that they are presumably important in carcinogenesis and tumor invasion. ${ }^{24-26}$

Pancreatic MUCs are classified in different categories: MUC1, MUC3, MUC4 are membrane-associated glycoproteins; MUC2, MUC5A, MUC5B and MUC6 are gel-forming mucins, and MUC7 is a soluble mucin. Normal pancreatic tissue expresses MUC1 mainly on the luminal surface of centro-acinar cells and in intra- and interlobular ducts, but not in the main pancreatic duct, acini, or islets. MUC2, MUC4, MUC5AC and MUC7 are not expressed in the normal pancreas. ${ }^{27}$

MUCs by IPMN histotype-Over 19 human MUC genes exist, and immunohistochemical MUC expression patterns can distinguish the different histopathologic types of IPMN (gastric, intestinal, pancreatobiliary). ${ }^{28-39}$ The gastric subtype of IPMN typically express MUC5AC but not MUC1 or MUC2 and are almost uniformly low-grade ${ }^{3}$, while the intestinal subtype of IPMN typically express MUC2. The pancreatobiliary subtype of IPMN typically express MUC1 and frequently contain high grade dysplasia. ${ }^{40,41}$ In some cases, studies using different antibodies for immunohistochemical analysis have given conflicting results and, in other cases, the lack of specific antibodies have made it difficult to perform appropriate functional studies.

Cyst fluid MUC levels measured by enzyme-linked immunoassays of aspirates from 40 patients found that gastric-subtype IPMN expressed lower levels of MUC2 ( $\mathrm{p}=0.02)$, MUC4 $(\mathrm{p}=0.02)$, and MUC5AC $(\mathrm{p}=0.04)$ compared to non-gastric cysts. There was no difference in MUC1 expression with very low or undetectable levels in the majority of cysts. Intestinal cysts contained higher levels of MUC2 $(\mathrm{p}=0.03)$ and tended to have increased levels of MUC4 ( $\mathrm{p}=0.05$ ) compared to non-intestinal cysts. Pancreatobiliary cysts were not significantly associated with a distinct mucin profile. ${ }^{42}$

MUCs by IPMN level of dysplasia-Numerous studies have evaluated the dysregulation of mucins in IPMNs, but the results are still controversial. Some studies revealed that IPMNs usually express MUC2, MUC5AC and mostly MUC4, whereas they don't express MUC1. ${ }^{34,35,39,43}$ This is in contrast to invasive ductal adenocarcinomas, which are characterized by an overexpression of MUC1 and the absence of MUC2. In a study of cyst fluid from patients with IPMN that underwent pancreatectomy, it was determined that MUC1 expression was very low in the cyst fluid across all groups of IPMN and that there was no correlation between MUC1 levels and the degree of cyst dysplasia. MUC5AC expression was much higher than MUC1 across all IPMN groups, but there was no association between the level of dysplasia and MUC5AC expression. On the other hand, MUC2 and MUC4 levels tended to cluster by the degree of dysplasia with higher levels of expression in highly dysplastic and invasive cystic lesions. ${ }^{42}$

MUCs in invasive adenocarcinoma-It has been demonstrated that non-invasive mucinous cystic neoplasms of the pancreas express MUC5AC and MUC2, and are MUC1- 
negative; compared to ductal adenocarcinoma where MUC1 is overexpressed in the invasive component and its expression correlated with a poor outcome. ${ }^{44}$ Masaki et al. specifically identified that sialynated MUC1 was detected in adenocarcinoma, whereas it was not observed in specimens from normal pancreas, chronic pancreatitis or ductal hyperplasia. ${ }^{45}$ Similarly, the de novo expression of MUC4 in adenocarcinoma and in pancreatic carcinoma cell lines has been reported. ${ }^{24,27,46,47}$ Both the $M U C l$ and $M U C 4$ genes encode numerous alternatively spliced isoforms, some of which are variants devoid of the mucin hallmark -the tandem repeat array. ${ }^{48}$ The role of these isoforms in IPMN histology remains to be determined.

MUC1 and MUC4 are implicated in almost all of the steps associated with the development of metastases as they possess anti-adhesive properties. ${ }^{23}$ These mucins are upregulated in pancreatic ductal adenocarcinoma where they also lose their strictly apical localization. The steric hindrance caused by the overexpression of the two extended glycoproteins disturbs the cell-cell and/or cell-matrix interactions with a mechanism that facilitates the release of tumor cells from the tissue into the circulation. ${ }^{49}$

One of the most recent studies on this topic demonstrated a significant change in mucin expression patterns in pancreatic adenocarcinoma throughout disease progression. MUC1 and MUC4 were differentially glycosylated as the disease progressed from early pancreatic intraepithelial neoplasia to metastatic disease. ${ }^{50}$ Additionally, a recent study evaluated cyst fluid RNA obtained by EUS-FNA for MUC expression in solid and cystic benign and malignant focal pancreatic lesions. ${ }^{51}$ The prevalence of MUC1, MUC2, MUC4, and MUC7 mRNA in ductal adenocarcinoma was 58, 51, 19, and 73.0\%, respectively. Sixty-three percent of IPMNs were positive for MUC1 and 47\% were positive for MUC2 expression. MUC7 expression was highly significant for adenocarcinoma $(p=0.007)$ and borderline for IPMN $(p=0.05)$. In this study, although there was not a difference in MUC7 expression in adenocarcinoma and chronic pancreatitis, MUC7 could be considered a potential marker of malignancy as it was positive in $73 \%$ of cancers. It could be useful in those cases where the cytological diagnosis is difficult because of a strong desmoplastic reaction or necrosis or, potentially, in cases in which a focal lesion with malignant evolution toward carcinoma grows in the context of an IPMN.

In summary, IPMNs have different histological patterns of growth and each histological subtype has a unique biology with different patterns of mucin expression (table 2). Though evaluation of mucin expression by immunohistochemistry, ELISA, and RNA analysis has proven feasible, and patterns of expression correlating with dysplasia and subtype have been identified; there is currently no established method for the preoperative subtype identification of IPMN. Cyst fluid mucin expression may hold promise for determination of invasive cancer, IPMN histologic subtype, and possibly the level of IPMN dysplasia.

\section{Cyst fluid cytokines and prostaglandins}

Inflammation and cancer have a complex interaction, often falling on either side of the spectrum of neoplasia. Pro-inflammatory cytokine-mediated inflammation has been shown to be associated with the pathogenesis of gastrointestinal malignancy ${ }^{52-55}$ Similarly, continued inflammation in the setting of chronic pancreatitis may lead to dysplasia and 
ultimately invasive pancreatic adenocarcinoma. However, inflammation may not only be a risk factor for adenocarcinoma, but it may also serve as a marker of neoplasia. Specific to IPMNs, it has been demonstrated that cytotoxic T-cells can be identified in the lesions and that there is a decrease in CD8+ cells with a corresponding increase in T-regulatory cells with increasing levels of cyst dysplasia. ${ }^{56}$ Cytokine markers of a Th1 and Th2 immune response have been shown to discriminate pancreatic cancer from chronic pancreatitis or normal pancreatic tissue in both serum and pancreatic juice samples. ${ }^{57,58}$ Inflammation in pancreatic IPMN may lead to severe dysplasia and be reflected in inflammatory mediators that can be measured in the cyst fluid. Alternatively, increasing levels of cyst dysplasia may initiate an immune response that can be quantified by evaluation of cyst fluid cytokines. In both instances, quantification of the immune response in IPMN cyst fluid may serve as a biomarker of dysplasia.

It follows, then, that inhibition of cytokine signaling may also be a marker of dysplasia. Aberrant methylation can silence the suppressor of cytokine signalling-1 (SOCS-1) gene, and when methylated it was found to be associated with $22 \%$ of tested pancreatic ductal adenocarcinomas and $6 \%$ of IPMNs, as opposed to no methylation in normal ductal epithelia, pancreatic intraepithelial neoplasia, or in non-invasive IPMNs. ${ }^{59}$

Exploratory analysis of cyst fluid from 5 IPMNs was performed utilizing a multiplex beadbased microarray protein assay that evaluated levels of 89 inflammatory mediator proteins. ${ }^{60}$ In this study, granulocyte-macrophage colony-stimulating factor (GM-CSF) and hepatocyte growth factor (HGF) were found to a greater degree in inflammatory cysts compared to IPMNs. The same assay was also used to compare BD-IPMN and mixed IPMN. ${ }^{61}$ The studies were limited by their exploratory nature and lack of statistical power or validation, but support the ability to measure multiple inflammatory mediators in the cyst fluid of IPMNs using a small volume of effluent $(<100 \mathrm{uL})$ to search for markers of specific cyst histotypes.

Utilizing a multiplex sandwich immunoassay of Th1/Th2 markers, the cyst fluid from 40 patients (19 high risk lesions with high grade dysplasia or invasive disease, and 21 low risk lesions with low or moderate grade dysplasia) were evaluated. In a univariate analysis, IL1 $\beta$, IL5, and IL8 had higher levels of expression in the presence of high grade dysplasia or invasive carcinoma. Multivariate analysis revealed that IL1 $\beta$ levels alone predicted high from low risk cysts, and remained a significant predictor on logistical regression when corrected for IPMN type (main or side branch) and cyst size. IL1 $\beta$ levels had a high sensitivity and specificity with a likelihood ratio of $17 \times$ to distinguish low from high risk cysts, and in a validation set maintained a high positive predictive value for correctly identifying high risk cysts, and a high negative predictive value for correctly identifying low risk cysts. ${ }^{62}$ Prostaglandins represent another molecular marker of inflammation that may be well disposed to measurement in IPMN cyst fluid. In a small number of patients with BD and MD-IPMNs, prostaglandinE2 (PGE2) levels in the cyst fluid were measured by ELISA and found to differentiate low from high risk (high grade dysplasia and invasive carcinoma) lesions. Prospective validation is warranted. ${ }^{63}$ 
In conclusion, there appears to be evidence of an immune cell infiltrate into IPMNs that may correspond with the level of dysplasia. Cyst fluid analysis of mediators of inflammation including IL1 $\beta$ and PGE2, in particular, could provide information that differentiate these groups.

\section{Cyst Fluid DNA Analysis}

DNA is a very stable molecule and less prone to degradation than RNA or proteins.

Importantly, neoplastic cells that line pancreatic cysts appear to shed their DNA into the cyst fluid. In 2009, the multicenter PANDA (Pancreatic Cyst DNA Analysis) study was conducted to investigate the role of genetic markers found in the pancreatic cyst fluid of 113 patients. ${ }^{64}$ The authors concluded that the presence of a KRAS mutation in the cyst fluid had $95 \%$ specificity and $45 \%$ sensitivity for diagnosing mucinous cysts. The combination of KRAS mutations and allelic loss yielded high specificity (96\%) but a low sensitivity (37\%) for distinguishing malignant from benign cysts. ${ }^{64}$ Subsequent studies have shown varied results using the same panel of markers ${ }^{65-69}$ and a recent prospective, single center study found that the accuracy of this panel was just over 50\% for identifying mucinous pancreatic cysts. $^{70}$

Initial studies based on a candidate gene approach identified a number of key genes frequently mutated in IPMNs, including KRAS, p16/CDKN2A, SMAD4, and TP53. ${ }^{71}$ Interestingly, these genes were also mutated in invasive pancreatic ductal adenocarcinoma (PDAC), although the prevalence of mutations in these genes was higher in invasive cancers than in IPMNs. ${ }^{71-76}$ Mutations in other genes, such as PIK3CA, LKB1/STK11 and BRAF have been also shown to occur in a small subset of IPMNs. ${ }^{77-79}$

Using parallel DNA sequencing, Wu et al. tested a panel of 169 cancer genes for the presence of somatic mutations in DNA from surgically resected IPMN. ${ }^{16}$ This confirmed a high mutational frequency of the KRAS gene and unexpectedly found frequent mutations in the GNAS gene, all located in the "hotspot" codon 201. More specifically, mutations in GNAS and KRAS were present in $66 \%$ and $81 \%$ of specimens, respectively, with a mutation in at least one of the two genes present in $95 \%$ of IPMNs. ${ }^{16}$ In contrast, no GNAS or KRAS mutations were identified in a large series of serous cystadenomas (SCA) and no GNAS mutations were present in other cyst types or in pancreatic adenocarcinoma. Whole-exome sequencing of mucinous pancreatic cysts found IPMNs characterized by KRAS, GNAS, RNF43, TP53, p16/CDKN2A and SMAD4 gene mutations and MCNs by KRAS, RNF43, TP53, p16/CDKN2A and SMAD4 gene mutations (Table 3). ${ }^{80}$

Only a few studies have validated the role of genetic alterations using next-generation sequencing. ${ }^{81-83}$ Amato et al. used next-generation targeted sequencing technology to assess the mutational status of 51 cancer genes in 48 surgically resected IPMNs. ${ }^{81}$ The authors showed that $96 \%$ of all IPMN analyzed harbored at least one mutated gene, with GNAS and KRAS being the most commonly mutated genes (79\% and 50\%, respectively). RNF43 was the third most frequently altered gene. In addition to these gene mutations, other mutations were found with lower frequency in TP53 (10\%) and BRAF (6\%). Furthermore, the authors performed deep sequencing on seven cyst fluid samples to assess the presence of the same mutations found in the microdissected neoplastic epithelial cells from corresponding IPMNs. 
Ten out of 13 mutations found in the tumors were also found in the cyst fluid samples, substantiating the feasibility of detecting mutant DNA molecules in cyst fluid, even when these mutant molecules were at a low concentration.

Other studies have confirmed the high prevalence of GNAS mutations in IPMNs, with mutations found in 57\%-64\% of cases of IPMNs. ${ }^{16,}$ 76, 80, 82 Although both $G N A S^{16,76,82}$ and $K R A S^{72,74-76}$ mutations occur commonly in patients with IPMNs, both mutations appear to occur early in the neoplastic transformation of IPMNs; specifically, KRAS mutations have been detected in over $90 \%$ of IPMNs with low- or intermediate-grade dysplasia. ${ }^{83,84}$ GNAS mutations, on the other hand, are found in IPMNs with low- through high-grade and invasive tumors. ${ }^{82,} 85$

Although cyst fluid genetic analysis has been predominantly centered on mutations of specific genes, another line of research has focused on epigenetic alterations. Hong et al. performed $\mathrm{CpG}$ island amplification followed by microarray analysis to compare the methylation status in IPMNs with normal pancreatic ductal epithelium. ${ }^{86}$ They found differential methylation in 2,259 genetic regions, and identified a series of genes including BNIP3, PTCHD2, SOX17, NXPH1, and EBF3, which were characteristically hypermethylated in IPMNs with high-grade compared with low-grade dysplasia.

There are limitations to DNA-biomarker analysis, and the studies conducted to date have analyzed surgically resected IPMN. Little is known about the genetic features of IPMNs undergoing surveillance, thus, there may be a bias in prevalence and clinico-pathological mutated genes as the lesions selected for operative intervention likely contained high-risk or worrisome features. Secondly, the prevalence of mutated genes varied between studies. Intra-tumor genetic heterogeneity may explain some of the variability observed, since various neoplastic clones are thought to develop within a neoplastic lesion. ${ }^{80}$ This highlights one of the limitations of molecular testing, which is that usually only a portion of a cyst is sampled.

In conclusion, DNA-based biomarkers may be used as diagnostic tools. However, further research is needed to identify a combination of genetic markers found only in the cyst fluid that will not only identify mucinous from serous lesions, but IPMN from MCN, and help identify patients with high-grade dysplasia or invasive disease, who may benefit from surgical resection. The authors find promise in further evaluation of KRAS and GNAS in cyst fluid in particular.

\section{Cyst Fluid miRNA Analysis}

Study of epigenetic mechanisms regulating the multistep processes involved in transcription or translation may provide insight into biomarkers associated with IPMN progression. ${ }^{87}$ MicroRNAs (miRNAs) are small (19 to 25 nucleotides) noncoding RNAs that regulate the stability and translation of mRNA transcripts. Micro-RNA evaluation is feasible due to their small size and stability in formalin-fixed, paraffin-embedded (FFPE) tissue $\mathrm{e}^{88}$ and biofluids. Deregulation has been recognized in numerous human malignancies, including pancreatic ductal adenocarcinoma, ${ }^{89}$ and specific miRNA expression patterns can discriminate between PanIN II and PanIN III lesions, ${ }^{90}$ and pancreatic adenocarcinoma from chronic 
pancreatitis. ${ }^{91,92}$ Elevated levels of miR-21 and miR-155 were identified in surgically resected specimens of non-invasive IPMNs and both were more frequently detected in IPMNs with carcinoma in-situ compared to non-invasive IPMNs. Follow-up assessment of cyst fluid from resected lesions identified significantly elevated concentrations of miR-21, miR-217, and miR-17-3p in mucinous (10 MCN, 16 IPMN) compared to non-mucinous cysts. $^{93}$

Assessment of FFPE sections from 65 invasive IPMNs and 16 non-invasive IPMNs supported a role for these particular microRNAs with miR-21 and miR-155 significantly overexpressed in invasive IPMN compared to non-invasive IPMNs, while the contrary relationship was observed for miR-101. ${ }^{94}$

Global miRNA expression analysis was examined in a study of 10 low grade, 5 moderate grade, 5 high grade, and 10 invasive IPMNs. ${ }^{95}$ Hierarchical clustering revealed 15 miRNAs that were different between low and intermediate-grade compared with high-grade and invasive IPMNs. Specifically, three miRNAs (miR-10a, miR-146 and miR-155) were elevated in high-grade and invasive IPMNs compared to low and moderate-grade IPMNs.

In an attempt to utilize miRNAs to discriminate high-grade dysplastic pancreatic cystic neoplasms likely to require surgical resection compared to those suitable for observation, high-throughput miRNA expression profiling was performed in low-grade $(\mathrm{n}=10)$ and high-grade $(\mathrm{n}=12)$ IPMN tissue as well as cyst fluid from 3 low-grade and 4 high-grade IPMNs. ${ }^{96}$ Subsequent qRT-PCR validation was performed in 23 IPMN tissues and 19 IPMN cyst fluid samples resulting in a subset of 18 miRNAs that discriminitated cysts requiring surgery (high-grade) from those suitable for observation (low-grade IPMNs). Logistic regression analysis led to the final identification of a 9-miRNA model, which allowed separation of all but one high-grade IPMN from low-grade IPMNs/SCAs with a sensitivity and specificity of $89 \%$ and $100 \%$, respectively. Of note miR-21 was upregulated in low-/ intermediate-/high-grade IPMNs, however, failed to predict the risk of malignant transformation. While limited by the mixed nature of the cysts that were assessed (IPMNs, SCAs, PNETs) this investigation highlighted the disparity in miRNA expression profiles between cyst fluid and resected tissue specimens, underlining the need for the development of a miRNA cyst fluid profile rather than extrapolation from resected tissue derived miRNA profiles.

Table 4 summarizes those miRNAs found dysregulated in IPMN tissue, cyst fluid, or serum. Certainly, further studies are needed to ascertain whether miRNA expression in cyst fluid and tumor tissue obtained with fine-needle aspiration biopsy can potentially differentiate high-grade from low-grade lesions.

\section{Conclusion}

Determination of the biologic behavior of an IPMN is critical to identify patients for whom surgical resection is indicated and potentially preventative or curative. Great strides have recently been made in study of the natural history of the disease and in establishing diagnostic criteria to better define IPMNs from other pancreatic cysts. What remains to be 
elucidated, however, is identification of IPMN at high-risk for malignant transformation or underlying malignancy, and a reliable molecular marker within the cyst fluid is needed. The status of EUS, EUS-FNA cytology, cyst fluid biochemistry, mucins, cytokines, DNA, and microRNA profiles in IPMN were critically reviewed. The group concluded that the ideal biomarker which could predict malignant potential should be easily obtained, widely applicable, and inexpensive. We predict that this molecular marker will likely be a conglomerate of the current known biomarkers explained herein, combined with additional proteomic analysis, and concluded that based on the available data, there is particular promise in creation of a biologic signature consisting of mucins 1, 2, 4, 5AC; IL1 $\beta$, PGE2, KRAS, GNAS, and the 9 miRNA panel. We forsee this signature as having a high positive predictive value and working alongside clinical factors that have already been validated such as mural nodularity, solid component, cyst growth rate, and duct obstruction; but having its greatest utility in the evaluation high risk pre-malignant cysts that are otherwise indistinguishable radiographically from benign cysts and those that will contain low-grade dysplasia indefinitely.

\section{Acknowledgment}

The authors wish to thank Professor Claudio Bassi for his insight, support, and vision for the meeting; Professor Roberto Salvia, Giovanni Marchegiani, and the scientific committee in Verona.

Support: Dr Maker received the Warren and Clara Cole Foundation Career Development Award and the AIMMC Research Grant; Drs Lennon and Molin received a Sol Goldman Pancreatic Cancer Research Center and Cancer Center Grant R01 CA176828; and Dr Scarpa received funding from the Fondazione Italiana Malattie del Pancreas (CUP_J33G13000210001), Associazione Italiana Ricerca sul Cancro (AIRC grant n. 12182).

\section{Abbreviations (in order of appearance)}

IPMN Intraductal papillary mucinous neoplasm of the pancreas

BD Branch-duct

MPD Main pancreatic duct

SCN Serous cystic neoplasm

MCN Mucinous cystic neoplasm

miRNA micro-ribonucleic acid

MUCs mucins

PDAC pancreatic ductal adenocarcinoma

\section{REFERENCES}

1. Fernández-Del Castillo C, Targarona J, Thayer SP, et al. Incidental pancreatic cysts: Clinicopathologic characteristics and comparison with symptomatic patients. Archives of Surgery. 2003; 138:427-434. [PubMed: 12686529]

2. Zhang XM, Mitchell DG, Dohke M, Holland GA, Parker L. Pancreatic cysts: Depiction on singleshot fast spin-echo MR images. Radiology. 2002; 223:547-553. [PubMed: 11997566]

3. Furukawa T, Klöppel G, Volkan Adsay N, et al. Classification of types of intraductal papillarymucinous neoplasm of the pancreas: A consensus study. Virchows Archiv. 2005; 447:794-799. [PubMed: 16088402] 
4. Hruban RH, Takaori K, Klimstra DS, et al. An illustrated consensus on the classification of pancreatic intraepithelial neoplasia and intraductal papillary mucinous neoplasms. American Journal of Surgical Pathology. 2004; 28:977-987. [PubMed: 15252303]

5. Maker AV, Lee LS, Raut CP, Clancy TE, Swanson RS. Cytology from pancreatic cysts has marginal utility in surgical decision-making. Annals of surgical oncology. 2008; 15:3187-3192. [PubMed: 18766406]

6. Takaori K. Current understanding of precursors to pancreatic cancer. J Hepatobiliary Pancreat Surg. 2007; 14:217-223. [PubMed: 17520195]

7. Ahmad NA, Kochman ML, Brensinger C, et al. Interobserver agreement among endosonographers for the diagnosis of neoplastic versus non-neoplastic pancreatic cystic lesions. Gastrointestinal endoscopy. 2003; 58:59-64. [PubMed: 12838222]

8. Sedlack R, Affi A, Vazquez-Sequeiros E, Norton ID, Clain JE, Wiersema MJ. Utility of EUS in the evaluation of cystic pancreatic lesions. Gastrointestinal endoscopy. 2002; 56:543-547. [PubMed: 12297771]

9. Cizginer S, Turner BG, Bilge AR, Karaca C, Pitman MB, Brugge WR. Cyst fluid carcinoembryonic antigen is an accurate diagnostic marker of pancreatic mucinous cysts. Pancreas. 2011; 40:10241028. [PubMed: 21775920]

10. Pitman MB, Lewandrowski K, Shen J, Sahani D, Brugge W, Fernandez-del Castillo C. Pancreatic cysts: preoperative diagnosis and clinical management. Cancer Cytopathol. 2010; 118:1-13. [PubMed: 20043327]

11. Rogart JN, Loren DE, Singu BS, Kowalski TE. Cyst wall puncture and aspiration during EUSguided fine needle aspiration may increase the diagnostic yield of mucinous cysts of the pancreas. Journal of clinical gastroenterology. 2011; 45:164-169. [PubMed: 20818233]

12. Terris, BFN.; Hruban, RH. Serous neoplasms of the pancreas. In: Bosman, FTCF.; Hruban, RH.; Theise, ND., editors. WHO classification of tumours of the digestive system. 4th ed.. Lyon: IARC; 2010. p. 296-299.

13. Yip-Schneider MT, Wu H, Dumas RP, et al. Vascular endothelial growth factor, a novel and highly accurate pancreatic fluid biomarker for serous pancreatic cysts. Journal of the American College of Surgeons. 2014; 218:608-617. [PubMed: 24491241]

14. Recine M, Kaw M, Evans DB, Krishnamurthy S. Fine-needle aspiration cytology of mucinous tumors of the pancreas. Cancer. 2004; 102:92-99. [PubMed: 15098253]

15. Woolf KM, Liang H, Sletten ZJ, Russell DK, Bonfiglio TA, Zhou Z. False-negative rate of endoscopic ultrasound-guided fine-needle aspiration for pancreatic solid and cystic lesions with matched surgical resections as the gold standard: one institution's experience. Cancer Cytopathol. 2013; 121:449-458. [PubMed: 23677908]

16. Wu J, Matthaei H, Maitra A, et al. Recurrent GNAS mutations define an unexpected pathway for pancreatic cyst development. Science translational medicine. 2011; 3 92ra66.

17. Centeno BA, Warshaw AL, Mayo-Smith W, Southern JF, Lewandrowski K. Cytologic diagnosis of pancreatic cystic lesions. A prospective study of 28 percutaneous aspirates. Acta cytologica. 1997; 41:972-980. [PubMed: 9250287]

18. Yamaguchi K, Enjoji M. Cystic neoplasms of the pancreas. Gastroenterology. 1987; 92:19341943. [PubMed: 3471621]

19. Walsh RM, Henderson JM, Vogt DP, et al. Prospective preoperative determination of mucinous pancreatic cystic neoplasms. Surgery. 2002; 132:628-633. discussion 33-4. [PubMed: 12407346]

20. Brugge WR, Lewandrowski K, Lee-Lewandrowski E, et al. Diagnosis of Pancreatic Cystic Neoplasms: A Report of the Cooperative Pancreatic Cyst Study. Gastroenterology. 2004; 126:1330-1336. [PubMed: 15131794]

21. Bafna S, Kaur S, Batra SK. Membrane-bound mucins: the mechanistic basis for alterations in the growth and survival of cancer cells. Oncogene. 2010; 29:2893-2904. [PubMed: 20348949]

22. Gendler SJ. MUC1, The renaissance molecule. Journal of Mammary Gland Biology and Neoplasia. 2001; 6:339-353. [PubMed: 11547902]

23. Moniaux N, Nollet S, Porchet N, Degand P, Laine A, Aubert JP. Complete sequence of the human mucin MUC4: a putative cell membrane-associated mucin. Biochem J. 1999; 338(Pt 2):325-333. [PubMed: 10024507] 
24. Hollingsworth MA, Strawhecker JM, Caffreyi TC, Mack DR. Expression of MUC1, MUC2, MUC3 and MUC4 mucin mrnas in human pancreatic and intestinal tumor cell lines. International Journal of Cancer. 1994; 57:198-203.

25. Yonezawa S, Goto M, Yamada N, Higashi M, Nomoto M. Expression profiles of MUC1, MUC2, and MUC4 mucins in human neoplasms and their relationship with biological behavior. Proteomics. 2008; 8:3329-3341. [PubMed: 18651706]

26. Yonezawa S, Sato E. Expression of mucin antigens in human cancers and its relationship with malignancy potential. Pathology International. 1997; 47:813-830. [PubMed: 9503463]

27. Andrianifahanana M, Moniaux N, Schmied BM, et al. Mucin (MUC) gene expression in human pancreatic adenocarcinoma and chronic pancreatitis: A potential role of MUC4 as a tumormarker of diagnostic significance. Clinical Cancer Research. 2001; 7:4033-4040. [PubMed: 11751498]

28. Adsay NV, Merati K, Basturk O, et al. Pathologically and biologically distinct types of epithelium in intraductal papillary mucinous neoplasms: Delineation of an "intestinal" pathway of carcinogenesis in the pancreas. American Journal of Surgical Pathology. 2004; 28:839-848. [PubMed: 15223952]

29. Chen Y, Zhao YH, Kalaslavadi TB, et al. Genome-Wide Search and Identification of a Novel GelForming Mucin MUC19/Muc19 in Glandular Tissues. American Journal of Respiratory Cell and Molecular Biology. 2004; 30:155-165. [PubMed: 12882755]

30. Dekker J, Rossen JWA, Büller HA, Einerhand AWC. The MUC family: An obituary. Trends in Biochemical Sciences. 2002; 27:126-131. [PubMed: 11893509]

31. Jass JR, Walsh MD. Altered mucin expression in the gastrointestinal tract: A review. Journal of Cellular and Molecular Medicine. 2001; 5:327-351. [PubMed: 12067494]

32. Lüttges J, Brocker V, Kremer B. Immunohistochemical mucin expression and DPC4 status in intraductal papillary mucinous tumors (IPMTs) of the pancreas. Pancreas. 2000; 21:459.

33. Lüttges J, Feyerabend B, Buchelt T, Pacena M, Klöppel G. The mucin profile of noninvasive and invasive mucinous cystic neoplasms of the pancreas. American Journal of Surgical Pathology. 2002; 26:466-471. [PubMed: 11914624]

34. Lüttges J, Zamboni G, Longnecker D, Klöppel G. The immunohistochemical mucin expression pattern distinguishes different types of intraductal papillary mucinous neoplasms of the pancreas and determines their relationship to mucinous noncystic carcinoma and ductal adenocarcinoma. American Journal of Surgical Pathology. 2001; 25:942-948. [PubMed: 11420467]

35. Nakamura A, Horinouchi M, Goto M, et al. New classification of pancreatic intraductal papillarymucinous tumour by mucin expression: Its relationship with potential for malignancy. Journal of Pathology. 2002; 197:201-210. [PubMed: 12015744]

36. Taylor-Papadimitriou J, Burchell JM, Plunkett T, et al. MUC1 and the immunobiology of cancer. Journal of Mammary Gland Biology and Neoplasia. 2002; 7:209-221. [PubMed: 12463741]

37. Yonezawa S, Horinouchi M, Osako M, et al. Gene expression of gastric type mucin (MUC5AC) in pancreatic tumors: Its relationship with the biological behavior of the tumor. Pathology International. 1999; 49:45-54. [PubMed: 10227724]

38. Yonezawa S, Nakamura A, Horinouchi M, Sato E. The expression of several types of mucin is related to the biological behavior of panceatic neoplasms. Journal of Hepato-Biliary-Pancreatic Surgery. 2002; 9:328-341. [PubMed: 12353144]

39. Yonezawa S, Taira M, Osako M, et al. MUC-1 mucin expression in invasive areas of intraductal papillary mucinous tumors of the pancreas. Pathology International. 1998; 48:319-322. [PubMed: 9648163]

40. Ban S, Naitoh Y, Mino-Kenudson M, et al. Intraductal papillary mucinous neoplasm (IPMN) of the pancreas: its histopathologic difference between 2 major types. The American journal of surgical pathology. 2006; 30:1561-1569. [PubMed: 17122512]

41. Nagata K, Horinouchi M, Saitou M, et al. Mucin expression profile in pancreatic cancer and the precursor lesions. Journal of Hepato-Biliary-Pancreatic Surgery. 2007; 14:243-254. [PubMed: 17520199]

42. Maker AV, Katabi N, Gonen M, et al. Pancreatic cyst fluid and serum mucin levels predict dysplasia in intraductal papillary mucinous neoplasms of the pancreas (IPMN). Annals of surgical oncology. 2010; 18:199-206. [PubMed: 20717734] 
43. Terris B, Dubois S, Buisine MP, et al. Mucin gene expression in intraductal papillary-mucinous pancreatic tumours and related lesions. Journal of Pathology. 2002; 197:632-637. [PubMed: 12210083]

44. Osako M, Yonezawa S, Siddiki B, et al. Immunohistochemical study of mucin carbohydrates and core proteins in human pancreatic tumors. Cancer. 1993; 71:2191-2199. [PubMed: 8384065]

45. Masaki Y, Oka M, Ogura Y, et al. Sialylated MUC1 mucin expression in normal pancreas, benign pancreatic lesions, and pancreatic ductal adenocarcinoma. Hepatogastroenterology. 1999; 46:2240-2245. [PubMed: 10521973]

46. Balague C, Gambus G, Carrato C, et al. Altered expression of MUC2, MUC4, and MUC5 mucin genes in pancreas tissues and cancer cell lines. Gastroenterology. 1994; 106:1054-1061. [PubMed: 8143972]

47. Balague C, Audie JP, Porchet N, Real FX. In situ hybridization shows distinct patterns of mucin gene expression in normal, benign, and malignant pancreas tissues. Gastroenterology. 1995; 109:953-964. [PubMed: 7657125]

48. Moniaux N, Andrianifahanana M, Brand RE, Batra SK. Multiple roles of mucins in pancreatic cancer, a lethal and challenging malignancy. Br J Cancer. 2004; 91:1633-1638. [PubMed: 15494719]

49. Komatsu M, Carraway CA, Fregien NL, Carraway KL. Reversible disruption of cell-matrix and cell-cell interactions by overexpression of sialomucin complex. J Biol Chem. 1997; 272:3324533254. [PubMed: 9407114]

50. Remmers N, Anderson JM, Linde EM, et al. Aberrant expression of mucin core proteins and olinked glycans associated with progression of pancreatic cancer. Clinical cancer research : an official journal of the American Association for Cancer Research. 2013; 19:1981-1993. [PubMed: 23446997]

51. Carrara S, Cangi MG, Arcidiacono PG, et al. Mucin expression pattern in pancreatic diseases: findings from EUS-guided fine-needle aspiration biopsies. Am J Gastroenterol. 2011; 106:13591363. [PubMed: 21647207]

52. Basso D, Scrigner M, Toma A, et al. Helicobacter pylori infection enhances mucosal interleukin-1 beta, interleukin-6, and the soluble receptor of interleukin-2. Int J Clin Lab Res. 1996; 26:207210. [PubMed: 8905454]

53. El-Omar EM, Carrington M, Chow WH, et al. Interleukin-1 polymorphisms associated with increased risk of gastric cancer. Nature. 2000; 404:398-402. [PubMed: 10746728]

54. Jung HC, Kim JM, Song IS, Kim CY. Helicobacter pylori induces an array of proinflammatory cytokines in human gastric epithelial cells: quantification of mRNA for interleukin-8, -1 alpha/ beta, granulocyte-macrophage colony-stimulating factor, monocyte chemoattractant protein-1 and tumour necrosis factor-alpha. J Gastroenterol Hepatol. 1997; 12:473-480. [PubMed: 9257236]

55. Noach LA, Bosma NB, Jansen J, Hoek FJ, van Deventer SJ, Tytgat GN. Mucosal tumor necrosis factor-alpha, interleukin-1 beta, and interleukin- 8 production in patients with Helicobacter pylori infection. Scand J Gastroenterol. 1994; 29:425-429. [PubMed: 8036458]

56. Hiraoka N, Onozato K, Kosuge T, Hirohashi S. Prevalence of FOXP3+ regulatory T cells increases during the progression of pancreatic ductal adenocarcinoma and its premalignant lesions. Clinical cancer research : an official journal of the American Association for Cancer Research. 2006; 12:5423-5434. [PubMed: 17000676]

57. Noh KW, Pungpapong S, Wallace MB, Woodward TA, Raimondo M. Do cytokine concentrations in pancreatic juice predict the presence of pancreatic diseases? Clinical gastroenterology and hepatology : the official clinical practice journal of the American Gastroenterological Association. 2006; 4:782-789. [PubMed: 16713745]

58. Seicean A, Popa D, Mocan T, Cristea V, Neagoe I. Th1 and Th2 profiles in patients with pancreatic cancer compared with chronic pancreatitis. Pancreas. 2009; 38:594-595. [PubMed: 19550277]

59. Fukushima N, Sato N, Sahin F, Su GH, Hruban RH, Goggins M. Aberrant methylation of suppressor of cytokine signalling-1 (SOCS-1) gene in pancreatic ductal neoplasms. Br J Cancer. 2003; 89:338-343. [PubMed: 12865927] 
60. Lee LS, Banks PA, Bellizzi AM, et al. Inflammatory protein profiling of pancreatic cyst fluid using EUS-FNA in tandem with cytokine microarray differentiates between branch duct IPMN and inflammatory cysts. J Immunol Methods. 2012; 382:142-149. [PubMed: 22683544]

61. Lee LS, Bellizzi AM, Banks PA, et al. Differentiating Branch Duct and Mixed IPMN in Endoscopically Collected Pancreatic Cyst Fluid via Cytokine Analysis. Gastroenterol Res Pract. 2012:247-309.

62. Maker AV, Katabi N, Qin LX, et al. Cyst fluid interleukin-1beta (IL1beta) levels predict the risk of carcinoma in intraductal papillary mucinous neoplasms of the pancreas. Clinical cancer research : an official journal of the American Association for Cancer Research. 2011; 17:1502-1508. [PubMed: 21266527]

63. Schmidt CM, Yip-Schneider MT, Ralstin MC, et al. PGE(2) in pancreatic cyst fluid helps differentiate IPMN from MCN and predict IPMN dysplasia. J Gastrointest Surg. 2008; 12:243249. [PubMed: 18027059]

64. Khalid A, Zahid M, Finkelstein SD, et al. Pancreatic cyst fluid DNA analysis in evaluating pancreatic cysts: a report of the PANDA study. Gastrointestinal endoscopy. 2009; 69:1095-1102. [PubMed: 19152896]

65. Sreenarasimhaiah J, Lara LF, Jazrawi SF, Barnett CC, Tang SJ. A comparative analysis of pancreas cyst fluid CEA and histology with DNA mutational analysis in the detection of mucin producing or malignant cysts. JOP : Journal of the pancreas. 2009; 10:163-168. [PubMed: 19287110]

66. Panarelli NC, Sela R, Schreiner AM, et al. Commercial molecular panels are of limited utility in the classification of pancreatic cystic lesions. The American journal of surgical pathology. 2012; 36:1434-1443. [PubMed: 22982886]

67. Shen J, Brugge WR, Dimaio CJ, Pitman MB. Molecular analysis of pancreatic cyst fluid: a comparative analysis with current practice of diagnosis. Cancer. 2009; 117:217-227. [PubMed: 19415731]

68. Sawhney MS, Devarajan S, O'Farrel P, et al. Comparison of carcinoembryonic antigen and molecular analysis in pancreatic cyst fluid. Gastrointestinal endoscopy. 2009; 69:1106-1110. [PubMed: 19249035]

69. Toll AD, Kowalski T, Loren D, Bibbo M. The added value of molecular testing in small pancreatic cysts. JOP : Journal of the pancreas. 2010; 11:582-586. [PubMed: 21068490]

70. Al-Haddad M, Dewitt J, Sherman S, et al. Performance characteristics of molecular (DNA) analysis for the diagnosis of mucinous pancreatic cysts. Gastrointestinal endoscopy. 2014; 79:7987. [PubMed: 23845445]

71. Hruban RH, Maitra A, Kern SE, Goggins M. Precursors to pancreatic cancer. Gastroenterology clinics of North America. 2007; 36:831-849. vi. [PubMed: 17996793]

72. Soldini D, Gugger M, Burckhardt E, Kappeler A, Laissue JA, Mazzucchelli L. Progressive genomic alterations in intraductal papillary mucinous tumours of the pancreas and morphologically similar lesions of the pancreatic ducts. The Journal of pathology. 2003; 199:453461. [PubMed: 12635136]

73. Iacobuzio-Donahue CA, Klimstra DS, Adsay NV. DPC-4 protein is expressed in virtually all human intraductal papillary mucinous neoplasms of the pancreas: Comparison with conventional ductal carcinomas. The American journal of pathology. 2000; 24:1544-1548.

74. Fritz S, Fernandez-del Castillo C, Mino-Kenudson M, et al. Global genomic analysis of intraductal papillary mucinous neoplasms of the pancreas reveals significant molecular differences compared to ductal adenocarcinoma. Annals of surgery. 2009; 249:440-447. [PubMed: 19247032]

75. Schonleben F, Qiu W, Bruckman KC, et al. BRAF and KRAS gene mutations in intraductal papillary mucinous neoplasm/carcinoma (IPMN/IPMC) of the pancreas. Cancer letters. 2007; 249:242-248. [PubMed: 17097223]

76. Furukawa T, Kuboki Y, Tanji E, et al. Whole-exome sequencing uncovers frequent GNAS mutations in intraductal papillary mucinous neoplasms of the pancreas. Scientific reports. 2011; 1:161. [PubMed: 22355676] 
77. Satoh K, Sasano H, Shimosegawa T, et al. An immunohistochemical study of the c-erbB-2 oncogene product in intraductal mucin-hypersecreting neoplasms and in ductal cell carcinomas of the pancreas. Cancer. 1993; 72:51-56. [PubMed: 8099533]

78. Schonleben F, Qiu W, Ciau NT, et al. PIK3CA mutations in intraductal papillary mucinous neoplasm/carcinoma of the pancreas. Clinical cancer research : an official journal of the American Association for Cancer Research. 2006; 12:3851-3855. [PubMed: 16778113]

79. Su GH, Hruban RH, Bansal RK, et al. Germline and somatic mutations of the STK11/LKB1 PeutzJeghers gene in pancreatic and biliary cancers. The American journal of pathology. 1999; 154:1835-1840. [PubMed: 10362809]

80. Wu J, Jiao Y, Dal Molin M, et al. Whole-exome sequencing of neoplastic cysts of the pancreas reveals recurrent mutations in components of ubiquitin-dependent pathways. Proceedings of the National Academy of Sciences of the United States of America. 2011; 108:21188-21193. [PubMed: 22158988]

81. Amato E, Molin MD, Mafficini A, et al. Targeted next-generation sequencing of cancer genes dissects the molecular profiles of intraductal papillary neoplasms of the pancreas. The Journal of pathology. 2014; 233:217-227. [PubMed: 24604757]

82. Dal Molin M, Matthaei H, Wu J, et al. Clinicopathological correlates of activating GNAS mutations in intraductal papillary mucinous neoplasm (IPMN) of the pancreas. Annals of surgical oncology. 2013; 20:3802-3808. [PubMed: 23846778]

83. Hong SM, Vincent A, Kanda M, et al. Genome-wide somatic copy number alterations in low-grade PanINs and IPMNs from individuals with a family history of pancreatic cancer. Clinical cancer research : an official journal of the American Association for Cancer Research. 2012; 18:43034312. [PubMed: 22723370]

84. Hong SK, Loren DE, Rogart JN, et al. Targeted cyst wall puncture and aspiration during EUSFNA increases the diagnostic yield of premalignant and malignant pancreatic cysts. Gastrointestinal endoscopy. 2012; 75:775-782. [PubMed: 22317883]

85. Kanda M, Knight S, Topazian MD, et al. Mutant GNAS detected in duodenal collections of secretin-stimulated pancreatic juice indicates the presence or emergence of pancreatic cysts. Gut. 2013; 62:1024-1033. [PubMed: 22859495]

86. Hong SM, Omura N, Vincent A, et al. Genome-wide CpG island profiling of intraductal papillary mucinous neoplasms of the pancreas. Clinical cancer research : an official journal of the American Association for Cancer Research. 2012; 18:700-712. [PubMed: 22173550]

87. Sato N, Matsubayashi H, Abe T, Fukushima N, Goggins M. Epigenetic down-regulation of CDKN1C/p57KIP2 in pancreatic ductal neoplasms identified by gene expression profiling. Clinical cancer research : an official journal of the American Association for Cancer Research. 2005; 11:4681-4688. [PubMed: 16000561]

88. Liu A, Tetzlaff MT, Vanbelle P, et al. MicroRNA expression profiling outperforms mRNA expression profiling in formalin-fixed paraffin-embedded tissues. International journal of clinical and experimental pathology. 2009; 2:519-527. [PubMed: 19636399]

89. Bloomston M, Frankel WL, Petrocca F, et al. MicroRNA expression patterns to differentiate pancreatic adenocarcinoma from normal pancreas and chronic pancreatitis. JAMA : the journal of the American Medical Association. 2007; 297:1901-1908.

90. Yu J, Li A, Hong SM, Hruban RH, Goggins M. MicroRNA alterations of pancreatic intraepithelial neoplasias. Clinical cancer research : an official journal of the American Association for Cancer Research. 2012; 18:981-992. [PubMed: 22114139]

91. Szafranska AE, Doleshal M, Edmunds HS, et al. Analysis of microRNAs in pancreatic fine-needle aspirates can classify benign and malignant tissues. Clinical chemistry. 2008; 54:1716-1724. [PubMed: 18719196]

92. Szafranska AE, Davison TS, John J, et al. MicroRNA expression alterations are linked to tumorigenesis and non-neoplastic processes in pancreatic ductal adenocarcinoma. Oncogene. 2007; 26:4442-4452. [PubMed: 17237814]

93. Ryu JK, Matthaei H, Dal Molin M, et al. Elevated microRNA miR-21 levels in pancreatic cyst fluid are predictive of mucinous precursor lesions of ductal adenocarcinoma. Pancreatology: official journal of the International Association of Pancreatology. 2011; 11:343-350. 
94. Caponi S, Funel N, Frampton AE, et al. The good, the bad and the ugly: a tale of miR-101, miR-21 and miR-155 in pancreatic intraductal papillary mucinous neoplasms. Annals of oncology : official journal of the European Society for Medical Oncology / ESMO. 2013; 24:734-741. [PubMed: 23139258]

95. Lubezky N, Loewenstein S, Ben-Haim M, et al. MicroRNA expression signatures in intraductal papillary mucinous neoplasm of the pancreas. Surgery. 2013; 153:663-672. [PubMed: 23305591]

96. Matthaei H, Wylie D, Lloyd MB, et al. miRNA biomarkers in cyst fluid augment the diagnosis and management of pancreatic cysts. Clinical cancer research : an official journal of the American Association for Cancer Research. 2012; 18:4713-4724. [PubMed: 22723372]

97. Habbe N, Koorstra JB, Mendell JT, et al. MicroRNA miR-155 is a biomarker of early pancreatic neoplasia. Cancer biology \& therapy. 2009; 8:340-346. [PubMed: 19106647]

98. Nakahara O, Takamori H, Iwatsuki M, et al. Carcinogenesis of intraductal papillary mucinous neoplasm of the pancreas: loss of microRNA-101 promotes overexpression of histone methyltransferase EZH2. Annals of surgical oncology. 2012; 19(Suppl 3):S565-S571. [PubMed: 21932133]

99. Li A, Yu J, Kim H, et al. MicroRNA array analysis finds elevated serum miR-1290 accurately distinguishes patients with low-stage pancreatic cancer from healthy and disease controls. Clinical cancer research : an official journal of the American Association for Cancer Research. 2013; 19:3600-3610. [PubMed: 23697990]

100. He H, Di Y, Liang M, et al. The microRNA-218 and ROBO-1 signaling axis correlates with the lymphatic metastasis of pancreatic cancer. Oncology reports. 2013; 30:651-658. [PubMed: 23733161]

101. Lee LS, Szafranska-Schwarzbach AE, Wylie D, et al. Investigating MicroRNA Expression Profiles in Pancreatic Cystic Neoplasms. Clinical and translational gastroenterology. 2014; 5:e47. [PubMed: 24476997]

102. Jiao LR, Frampton AE, Jacob J, et al. MicroRNAs targeting oncogenes are down-regulated in pancreatic malignant transformation from benign tumors. PloS one. 2012; 7:e32068. [PubMed: 22384141]

103. Aso T, Ohtsuka T, Tamura K, et al. Elevated expression level of MicroRNA-196a is predictive of intestinal-type intraductal papillary mucinous neoplasm of the pancreas. Pancreas. 2014; 43:361366. [PubMed: 24622064] 


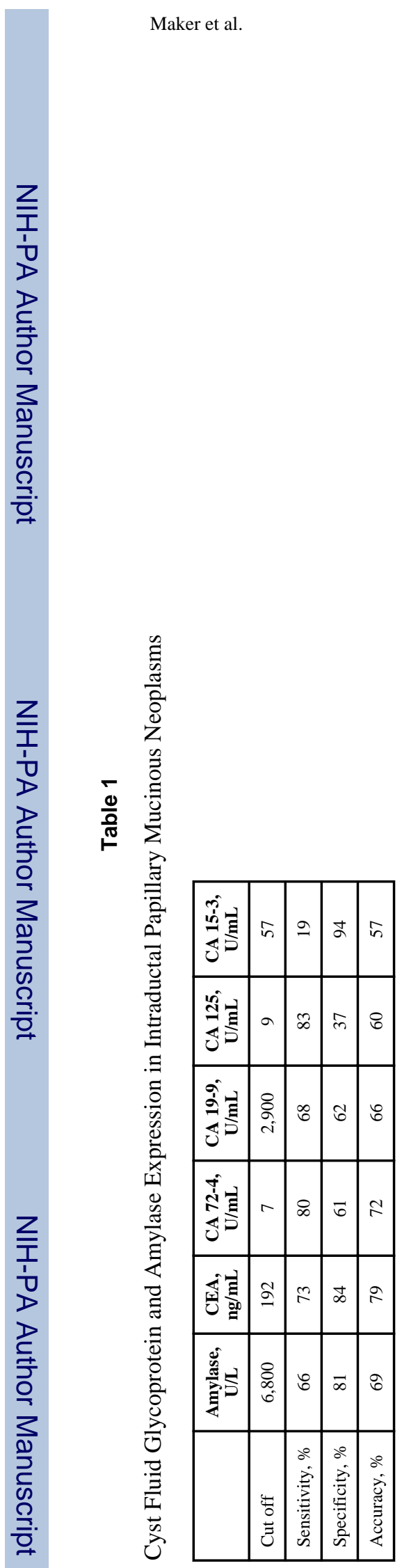

J Am Coll Surg. Author manuscript; available in PMC 2016 February 01. 


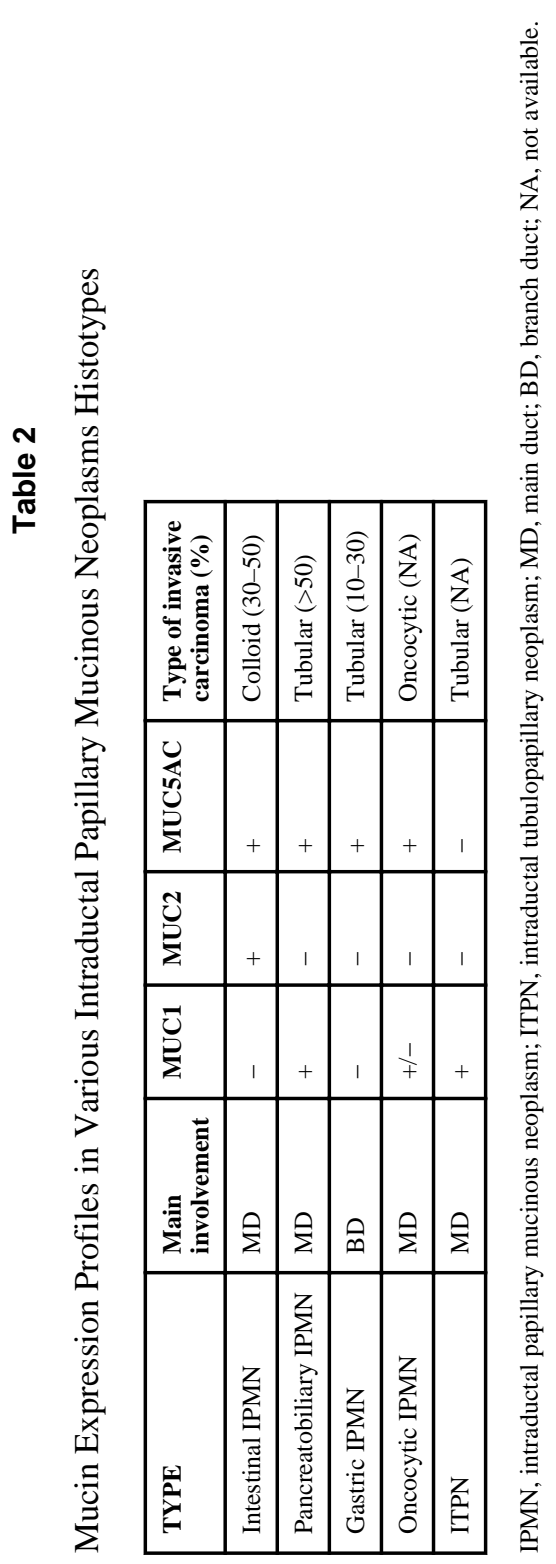

J Am Coll Surg. Author manuscript; available in PMC 2016 February 01. 


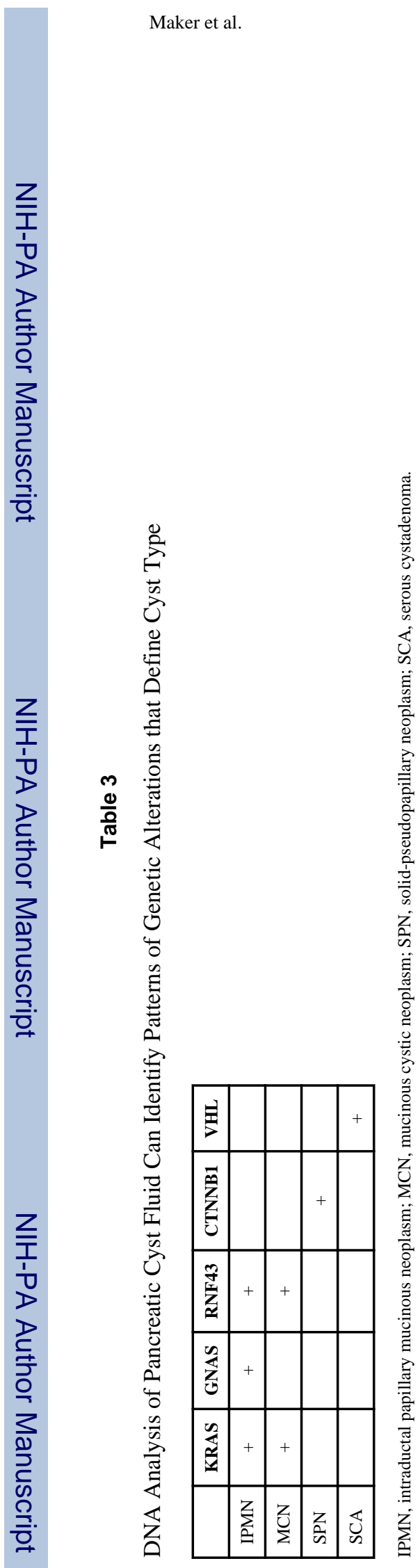

$J$ Am Coll Surg. Author manuscript; available in PMC 2016 February 01. 
Table 4

MicroRNAs Associated with Various Histologic Classifications of Intraductal Papillary Mucinous Neoplasms

\begin{tabular}{|c|c|c|c|c|}
\hline Histologic classification of IPMN & First author & Tissue Source & Up-regulated & Down-regulated \\
\hline \multicolumn{5}{|l|}{ Lesion } \\
\hline \multirow[t]{2}{*}{ Non-invasive IPMN } & $\begin{array}{l}\text { Habbel }^{97}, \text { Caponi }^{94} \text {, } \\
\text { Nakhara }^{98}\end{array}$ & Tissue & $\begin{array}{l}\text { miR-21, miR-155, } \\
\text { miR-107, miR-223, } \\
\text { miR-181c, miR-181a, } \\
\text { miR-221, miR-210, } \\
\text { miR-16, miR-100 }\end{array}$ & miR-101 \\
\hline & $\mathrm{Li}^{99}$ & Serum & miR-1290 & -- \\
\hline Invasive IPMN & $\begin{array}{l}\text { Lubezky }^{95}, \\
\text { Caponi }^{94}, \mathrm{He}^{100}\end{array}$ & Tissue & $\begin{array}{l}\text { miR-21, miR-155, } \\
\text { miR-708 }\end{array}$ & $\begin{array}{l}\text { miR-101, miR-217, } \\
\text { miR-218 }\end{array}$ \\
\hline \multirow[t]{3}{*}{ PDAC vs non-invasive IPMN } & $\mathrm{Lee}^{101}$ & Tissue & miR-21-5p, miR-708 & $\begin{array}{l}\text { miR-485-3p, miR- } \\
375\end{array}$ \\
\hline & Jiao $^{102}$ & Tissue & & miR-16, miR-126 \\
\hline & $\mathrm{Li}^{99}$ & Serum & $\operatorname{miR}-1290$ & -- \\
\hline \multicolumn{5}{|l|}{ Degree of dysplasia } \\
\hline HG IPMN & Lubezky $^{95}$, Habbe $^{97}$ & Tissue & $\begin{array}{l}\text { miR-10a, miR-21, } \\
\text { miR-146, miR-155 }\end{array}$ & -- \\
\hline IG IPMN & Lubezky ${ }^{95}$, Habbe $^{97}$ & Tissue & $\begin{array}{l}\text { miR-21, miR-155, } \\
\text { miR-708 }\end{array}$ & $\operatorname{miR}-217$ \\
\hline LG IPMN & Lubezky $^{95}$, Habbe $^{97}$ & Tissue & $\begin{array}{l}\text { miR-21, miR-155, } \\
\text { miR-708 }\end{array}$ & $\mathrm{miR}-217$ \\
\hline \multirow[t]{2}{*}{$\begin{array}{l}\text { HG/Invasive IPMN vs LG/IG } \\
\text { IPMN }\end{array}$} & Lubezky ${ }^{95}$ & Tissue & $\begin{array}{l}\text { miR-21, miR-146a, } \\
\text { miR-150, miR-214, } \\
\text { miR-503, miR-424, } \\
\text { miR-708, miR-155 }\end{array}$ & $\begin{array}{l}\text { miR-217, miR-216a, } \\
\text { miR-216b, miR-148, } \\
\text { miR-375, miR-130b }\end{array}$ \\
\hline & Matthei ${ }^{96}$ & Tissue, cyst fluid & $\begin{array}{l}\text { miR-18a, miR-24, } \\
\text { miR-30a-3p, miR- } \\
\text { 92a, miR-99b miR- } \\
\text { 106b, miR-142-3p, } \\
\text { miR-342-3p, miR- } \\
\text { 532-3p }\end{array}$ & DiffPairs analysis \\
\hline $\begin{array}{l}\text { LG IPMN vs HG IPMN with } \\
\text { evidence of invasion }\end{array}$ & Lubezky ${ }^{96}$ & Tissue & $\begin{array}{l}\text { miR-10a, miR-21, } \\
\text { miR-24-2, miR-132, } \\
\text { miR-146a, miR-146b, } \\
\text { miR-155, miR-196, } \\
\text { miR-424, miR-503, } \\
\text { miR-708 }\end{array}$ & $\begin{array}{l}\text { miR-217, miR-216a, } \\
\text { miR-216b, miR-148, } \\
\text { miR-375, miR-130b }\end{array}$ \\
\hline \multicolumn{5}{|l|}{ IPMN morphological subtype } \\
\hline Intestinal & Aso $^{103}$, Habbe $^{97}$ & Tissue, serum & $\begin{array}{l}\text { miR-196a, miR-21, } \\
\text { miR-155 }\end{array}$ & -- \\
\hline Gastric & Habbe $e^{97}$ & Tissue & -- & miR-155 \\
\hline
\end{tabular}

IPMN, intraductal papillary mucinous neoplasm; HG, high grade; IG, intermediate grade; LG, low grade; PDAC, pancreatic ductal adenocarcinoma. 